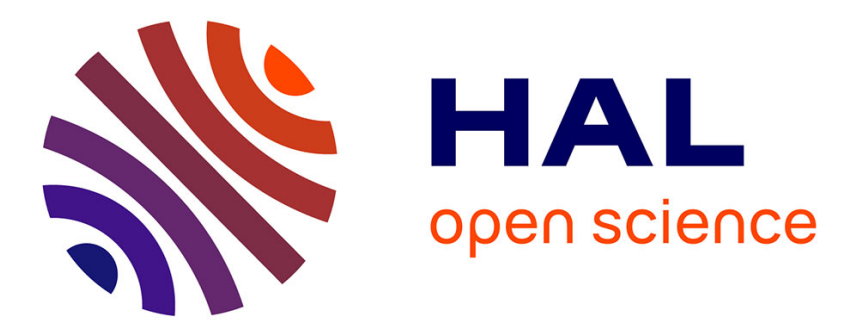

\title{
Kean Birch, 2019, Neoliberal Bio-Economies? The Co-Construction of Markets and Natures Palgrave MacMillan, $208 \mathrm{p}$
}

Benjamin Raimbault

\section{- To cite this version:}

Benjamin Raimbault. Kean Birch, 2019, Neoliberal Bio-Economies? The Co-Construction of Markets and Natures Palgrave MacMillan, 208 p. Review of Agricultural, Food and Environmental Studies, 2021, 102 (1), pp.115-119. 10.1007/s41130-021-00136-0 . hal-03559527

\section{HAL Id: hal-03559527 \\ https://hal.science/hal-03559527}

Submitted on 7 Feb 2022

HAL is a multi-disciplinary open access archive for the deposit and dissemination of scientific research documents, whether they are published or not. The documents may come from teaching and research institutions in France or abroad, or from public or private research centers.
L'archive ouverte pluridisciplinaire HAL, est destinée au dépôt et à la diffusion de documents scientifiques de niveau recherche, publiés ou non, émanant des établissements d'enseignement et de recherche français ou étrangers, des laboratoires publics ou privés. 


\title{
Kean Birch, 2019, Neoliberal Bio-Economies? The Co-Construction of Markets and Natures Palgrave MacMillan, $208 \mathrm{p}$
}

\author{
Benjamin Raimbault ${ }^{1}$
}

Accepted: 5 January 2021 / Published online: 4 February 2021

(C) INRAE and Springer-Verlag France SAS, part of Springer Nature 2021, corrected publication 2021

Kean Birch, associate professor at Canada's University of York, has written a welldocumented and succinct essay on the constituent links of the relations between nature and the economy. As responses to the climate emergency are confronted with the inertia of socioeconomic systems that depend on fossil fuels, "Neoliberal Bio-Economies?" is an investigation into what the author presents as one of the few options for the transition to a low-carbon future, namely the bio-economy "that refers to the sustainable use of biological, renewable materials in the development of bio-based products, services and energy that substitute for existing fossil fuel-based products, services and energy, as part of a broader societal transition to a low-carbon future" (p. 70).

The study's intention and structure constitute a key step for its author. Firstly, dividing the book into eight relatively autonomous chapters summarises the result of ten years of research devoted to the study of the bio-economy in France and Canada, which gave rise to several publications. Secondly, "Neoliberal Bio-Economies?" marks the theoretical reorientation of an author who for a long time adopted a critical stance with regard to neoliberalism and who, in light of the climate emergency, seeks to assess the possible solutions to the global ecological crisis, starting out from the existing socioeconomic order.

This stance accompanies the study's main argument, namely that it is impossible to dissociate the construction of the market and the construction of nature. This coproductionist bias, well-known in the Sciences and Technology Studies (STS) circles the author is part of, is presented and positioned within the abundant literature on neoliberalism in Chapter 2. The presentation of a very clear typology of the literature on the relations between neoliberalism and nature (p. 24) enables Birch to distance himself from two implicit hypotheses that underlie these studies, that is to say (1) that material nature is transformed by social processes and (2) that markets are disruptors of a pristine material nature (p. 26). The study of the co-construction of markets and natures

Benjamin Raimbault

raimbault.benjamin6@gmail.com

1 IFRIS, Laboratoire Interdisciplinaire Sciences Innovations Sociétés, Université Gustave Eiffel, 77454 Marne-la-Vallée, France 
is then envisaged from a theoretical framework at the crossroads between environmental economic geography, studies on socio-technical transitions and STS. These three research fields are connected by an attention to materiality, whether this is the mechanisms of the political economy considered (not only value creation but also the material transformations that involve commercial exchange), that of mediations between the economy and nature (markets as sociomaterial assemblages) or those of socio-technical systems.

Based on 39 interviews conducted with policy-makers, business people, trade associations, energy experts, civil society organisations and associations as well as the study of reports from provincial institutions, the survey focuses on the Canadian case of advanced biofuels, one of the biggest and most visible sectors of the bioeconomy. Also known as "drop-in" biofuels, advanced biofuels are characterised by a functional equivalence with petroleum-based fuels, thus making them compatible with the infrastructure, institutions and oil markets already in place.

This choice is explained in Chapter 3, which gives the author space to specify the boundaries and definitions of the bio-economy. Birch shows how, with the oil crisis in the 1970 s and then the emergence of climate issues in the $2000 \mathrm{~s}$, biofuels were considered as a possible - although contested - alternative to the use of oil in many countries (USA, European Union, Canada and Brazil). Recently, biofuels were incorporated into the bio-economy agenda that has come to be one of the reference frameworks for major public environmental action in certain international institutions (OECD, EC), with the aim of reconciling economic development and the consideration of climate issues. The author stresses the diversity of the socio-technical trajectories taken (USA and maize, Brazil and sugarcane) as well as the great flexibility of the term bio-economy that enables him to situate it as an institutional production that is completely compatible with the existing socioeconomic order but also as a potential alternative form.

In Chapter 4, the author sets out to identify how visions of the bio-economy are incorporated into policy frameworks by emphasising the discursive dimension accompanying the bio-economy boom. He identifies four concurrent political visions of the bio-economy: a dominant "product-based" vision that equates the bio-economy with the production of new goods made from biomass; a similar vision, known as "substitution", which aims to replace fossil fuel-based energies making it possible to retain existing production infrastructure; a vision highlighting the ambiguity between a sustainable and renewable bio-economy; and lastly a vision qualified by societal transitions calling for a radical and interdisciplinary transformation of production modes. The difficulty in identifying a differentiating factor between these visions is due to the fragmented nature of the Canadian public policy framework, itself due to both the specificity of the administration and the influence of industry. On the one hand, each province has the sovereignty to manage and guide its economic policies, which leads to a multiplication of frameworks relative to the type of regional resources. On the other hand, the dominant vision is based on the development of new products championed by industrial stakeholders who lobby for sectoral support.

Chapters 5 and 6 analyse biofuels' political and economic materialities in what they allow and limit from the point of view of market constructions. Birch examines the convergence of public policies and the socio-technical system towards advanced biofuels at the expense of conventional biofuels (ethanol or biodiesel made from crops 
such as sugarcane, wheat or soya), which he explains by their capacity to be integrated into petroleum uses and production modes, and by the non-food nature of the biomass used. Birch details that the four mechanisms deployed by the public authorities (market development policies or MDPs) to develop the production of these biofuels (mandates, subsidies, feedstock supply, standards) are both index-linked and put to the test by the biomass conversion limit, the low energy density of biofuels and the area of land needed to replace the use of fossil fuel-based energy. The obligation to incorporate a certain proportion of biofuels into fuel (mandate) guarantees demand and allows the biofuel market to grow. The conditions and scope of this obligation are not exclusively political; they also depend on the materiality of biofuels. Thus, Northern Ontario is not concerned by the introduction of $5 \%$ ethanol in the fuel mix because of the extreme weather conditions that freeze biodiesel. The second example involves the measures taken to organise and configure access to and the availability of biomass (feedstock supply) that has to take into consideration its materiality. The low energy density limits the circulation of the resource and forces economic actors into a certain "loyalty" in their procurement (p. 149). In the same way, the seasonal nature of crops hampers the continuous supply of the raw materials necessary for production. Material properties therefore limit the forms of public action that are focused on developing transport infrastructure or waste collection.

The study's argument is summarised in Chapter 7 through a series of steps of the biofuel value chain, used as a medium to show how economic and natural processes are inter-related. The author describes how-whether upstream when biofuels are converted, or when they are distributed - biofuel markets and the nature from which biomass is produced are the product of large infrastructural machinery; this, although supported by the public authorities, is confronted with the inertia of petroleum production and consumption modes. Upstream, developing biofuels is conditioned by the availability of biomass, which is not a strictly biophysical parameter but dependent on transport infrastructure and the monitoring of forestry by the public authorities. Downstream, the development of "agnostic" conversion technologies for resources (p. 177)-i.e. compatible with a wide range of biomasses in processes - can be explained by the potential to valorise marginal agricultural land and waste, the constraint of assorted natural resources and the need to produce standardised goods that can be exchanged.

This study is outstanding for its erudition and summaries of research into both neoliberalism and the bio-economy. Readers may, however, regret the impression of repetition in certain theoretical developments, detracting slightly from the core argument and a reminder that the book brings together several studies that have already been published. More profoundly, the focal depth Birch offers into the importance of materiality in the co-construction of markets and natures is particularly welcome. On the one hand, it invites approaches in terms of political economics to better incorporate the way in which the specificities of natural goods enable and limit the construction of markets, and to consider the production processes in the regulation of market exchange. On the other hand, Birch's theoretical framework suggests shifting away from many bio-economy discourses that are still the chosen angle for analyses today.

However, this shift is not entirely successful for three reasons. The first reason involves the empirical material used, which is composed exclusively of official reports and the narrative of stakeholders, most of whom are committed to the success of the bio-economy. Despite the diversity of the profiles of those interviewed, we should 
consider addressing the question of materiality without integrating an analysis of the concrete practices of stakeholders committed to stabilising the value chains described, or give a detailed description of the processes and infrastructure concerned. The proposed shift from the study of value creation to that of material transformations could lead us to analyse the commercial act via its productive dimension. It might then be relevant to go a step further by studying how the work and processes to coordinate the human and non-human aspects involved in material transformation are also materially constituted (type of contractualisation, employment dynamics, and professional risk management).

The second reason lies in the scarcity of cases for the study of the epistemic dimensions associated with materiality. Despite his reference to studies by Timothy Mitchell and the way in which Mitchell suggests seeing in the materiality of energy a source for democracies' political models in the famous Carbon Democracy, Birch gives only superficial descriptions of the epistemic infrastructure and practices accompanying the bio-economy boom. What type of expertise is constituted? To what extent is the bio-economy reviving the thinking of unorthodox economists (such as GeorgescuRoegen) and does it modify power relations in economic sciences? A perspective such as this would perhaps have made it possible to formulate a hypothesis about the study's initial observation that the "bio-economy is a rather high-level policy or expert concept that most publics have simply never heard about" (p. 2) by seeing in it the product of the removal of economic choices from democratic control by certain experts and economic institutions.

Lastly, the significance of materiality in Birch's argumentation could have provided the opportunity for a new discussion of the entire STS literature attentive to the specificity of living things (Waldby 2000; Rose 2001; Rajan 2006; Cooper 2008) in establishing the bio-economy. Elsewhere, the author has already dismissed these approaches for their "fetishization of all things "bio"" (Birch and Tyfield 2013) and the fact that they do no employ political economics' classic frameworks. Quite rightly, Birch had pointed how important it is for a study of the bio-economy to analyse the forms of associated work and the bio-economy's integration into a techno-scientific capitalism dominated by assetization processes (Birch and Muniesa 2020). While these criticisms are perfectly legitimate, the exclusion of bio-centred studies also excludes an entire section of the bio-economy based on the medical and bio-medicine sector. This is a pity, because medical applications are incorporated into certain institutional definitions of the bio-economy (OECD, 2009), and the financial and political stakes of this sector are considerable.

These remarks in no way detract from the fact that Birch's study is a salutary compass to find one's way among the meanderings of the bio-economy and to position it in a wider discussion about the relationships between the economy and the environment, as well as indicating stimulating research avenues to explore.

\section{References}

Birch, K., \& Muniesa, F. (Eds.). (2020). Assetization: turning things into assets in technoscientific capitalism. MIT Press, Cambridge, Massachusetts. 
Birch, K., \& Tyfield, D. (2013). Theorizing the bioeconomy: biovalue, biocapital, bioeconomics or... what? Science, Technology, \& Human Values, 38(3), 299-327.

Cooper, M. (2008). Life beyond the limits: inventing the bioeconomy. Life as Surplus: Biotechnology and Capitalism in the Neoliberal Era, 15-50.

Organisation for Economic Co-operation and Development (OECD). (2009). The Bioeconomy to 2030: Designing a Policy Agenda; Organisation for Economic Co-operation and Development (OECD): Paris, France.

Rajan, K. S. (2006). Biocapital: the constitution of postgenomic life. Duke University Press, Durham, North Carolina.

Rose, N. (2001). The politics of life itself. Theory, culture \& society, 18(6), 1-30.

Waldby, C. (2000). The visible human project: informatic bodies and posthuman medicine. Psychology Press, London: Routledge.

Publisher's note Springer Nature remains neutral with regard to jurisdictional claims in published maps and institutional affiliations. 